\title{
cDNA and Derived Amino Acid Sequence of Rabbit Nasal Cytochrome P450NMb (P450IIG1), a Unique Isozyme Possibly Involved in Olfaction ${ }^{1}$
}

\author{
Xinxin Ding, Todd D. Porter, Hwei-Ming Peng, and Minor J. Coon ${ }^{2}$ \\ Department of Biological Chemistry, Medical School, The University of Michigan, Ann Arbor, Michigan 48109-0606
}

Received September 18, 1990, and in revised form October 16, 1990

Olfactory-specific cytochrome P450NMb was previously purified to electrophoretic homogeneity from microsomes of rabbit nasal mucosa in this laboratory. In the present study, a cDNA library made from poly $(A)^{+}$ RNA from rabbit nasal mucosa was screened with antibodies to this $\mathbf{P 4 5 0}$, and eight immunopositive clones were isolated and characterized. The sequence determined from two overlapping clones contained an open reading frame of 1446 nucleotides, with the predicted first 39 amino acids corresponding to residues 12 to 50 of purified $\mathrm{NMb}$, except for position 46, where Leu was encoded instead of the Glu residue that was found earlier by Edman degradation analysis. The complete polypeptide, including residues 1 to 11 , contains 494 amino acid residues and has a molecular weight of 56,640 . Sequence comparisons indicated that $\mathrm{NMb}$ is more than $50 \%$ identical to members of the rabbit $\mathbf{P 4 5 0}$ gene II family, including IIB4, IIC3, IIC5, IIE 1, and IIE2, and $83 \%$ identical to rat P450olf1 (IIG1). Hybridization of NMb to electrophoretically fractionated rabbit nasal poly(A) ${ }^{+}$ RNA revealed 3.6- and 2.1-kb species, but with a probe derived from the 3 '-nontranslated portion of the cDNA only the 3.6-kb band was observed, suggesting the use of alternate polyadenylation sites or splicing. In agreement with the known tissue-specific distribution of NMb protein, $\mathrm{NMb}$ transcripts were found in olfactory mucosa, but not in liver, lung, intestine, or kidney. Genomic hybridization analysis indicated that there may be only one copy of the NMb gene present in the rabbit genome. (C) 1991 Academic Press, Inc.

\footnotetext{
${ }^{1}$ This investigation was supported by Grant DK-10339 from the Na-

tional Institutes of Health.
${ }^{2}$ To whom correspondence should be addressed at Department of

${ }^{2}$ To whom correspondence should be addressed at Department of Biological Chemistry, Medical School, University of Michigan, 1301 Catherine Road, Ann Arbor, MI 48109-0606. Fax (313) 763-4581.
}

A large number of structurally related monooxygenases of the P450 gene superfamily, most of which are found in the liver in mammals, have been characterized $(1,2)$. However, some of the P450 forms, such as those involved in the synthesis of steroid hormones, are selectively expressed in specific extrahepatic tissues (3). Recently, two unique forms of $\mathrm{P} 450$, termed $\mathrm{NMa}^{3}$ and $\mathrm{NMb}$, were isolated from rabbit nasal microsomes in our laboratory (4). Subsequent immunochemical studies (5) indicated that both NMa and NMh are major isozymes in microsomal preparations from olfactory mucosa, and that, while NMa is found in both olfactory and respiratory nasal mucosa and also in liver, $\mathrm{NMb}$ is found only in the olfactory mucosa and not in a variety of other tissues examined, including brain, heart, intestine, kidney, liver, lung, esophageal mucosa, and respiratory nasal mucosa. The presence in olfactory mucosa of unique forms of P450 monooxygenases, as well as relatively high levels of other related biotransformation enzymes, such as NADPH-cytochrome P450 reductase $(6,7)$, may be important for maintaining acuity in the sense of smell $(8,9)$.

The first 50 amino acid residues at the amino terminus of purified $\mathrm{NMb}$ were identified previously by automated Edman degradation analysis (4). A comparison of the $\mathrm{NH}_{2}$-terminal sequence of $\mathrm{NMb}$ with that of other rabbit P450s suggests that this nasal-specific cytochrome may belong to the P450II gene family. This is supported by the finding that polyclonal antibodies against purified $\mathrm{NMb}$ exhibit weak cross-reactivity with members of the gene II family but not with members of other gene families (5). To establish definitively the structural relationship between $\mathrm{NMb}$ and other $\mathrm{P} 450$ isozymes, we have used monospecific anti-NMb antibodies to obtain clones for $\mathrm{NMb}$ from a rabbit nasal cDNA library, and we now report

\footnotetext{
${ }^{3}$ Abbreviations used: NMa and NMb, nasal microsomal cytochrome P450 forms a and b, respectively; kb, kilobase(s); SDS, sodium dodecyl sulfate; PAGE, polyacrylamide gel electrophoresis; bp, base pair(s).
} 


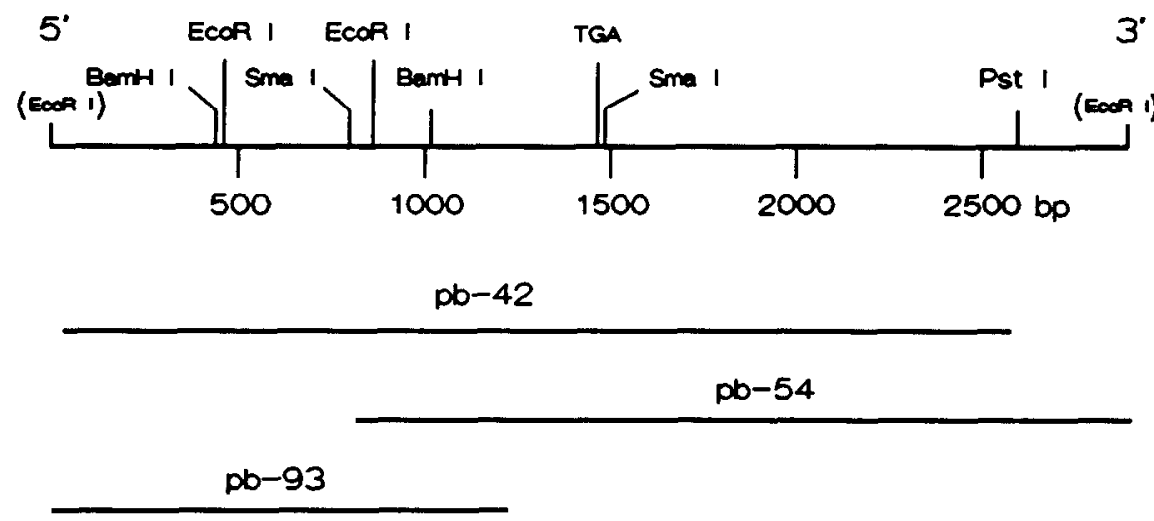

FIG. 1. Restriction map of cDNA clones encoding P450NMb. The cDNA inserts were cloned into the EcoRI site (in parentheses) in the polylinker region of $\lambda$ ZAP II.

the entire derived amino acid sequence of P450 NMb. Sequence comparison shows that this $\mathrm{P} 450$ is indeed a member of the P450Il gene family and, furthermore, that it is highly similar to a rat cytochrome, P450olf1, or IIG1, for which a cDNA was recently characterized by Nef et al. (9). Genomic DNA analysis suggests that the P450IIG gene subfamily may contain only a single gene in the rabbit and that at least one copy of the homologous form is present in the human genome.

\section{MATERIALS AND METHODS}

Total cellular RNA was isolated from frozen nasal mucosa from untreated male adult New Zealand White rabbits by the guanidinium thiocyanate extraction method of Chirgwin et al. (10). Polyadenylated RNA purified from total RNA by oligo(dT) -cellulose chromatography (11) was used for the construction of a cDNA library in the $\lambda$ ZAP II vector by Stratagene Cloning Systems (La Jolla, CA). The library was amplified in XL1-Blue cells (Stratagene). Approximately $5 \times 10^{5}$ phage particles from the amplified library were screened with a monospecific sheep anti$\mathrm{NMb}$ antibody (5) according to the general method described by Mierendorf et al. (12) with the use of peroxidase-conjugated rabbit antisheep IgG for immunochemical detection. Positive phage clones were plaque-purified, and the $\beta$-galactosidase fusion proteins were further analyzed by immunoblotting with anti-NMb IgG. The pBluescript SKdouble-stranded phagemids with cloned DNA inserts were then prepared according to the protocol described in the Instruction Manual for the $\lambda$ ZAP Cloning Kit and characterized by restriction mapping. Partially deleted subclones of the pBluescript SK- recombinants, obtained with the Double-stranded Nested Deletion Kit from Pharmacia, were sequenced by the chain-termination method (13) with Sequenase Version 2.0 from United States Biochemicals Corp. For sequence determination of the reverse strand, the DNA inserts were first subcloned into either pBluescript SK+ or M13 mp19 (BRL) before the nested unidirectional deletion constructs were made. Sequence data were analyzed by use of the Beckman Microgenie Program. Each nucleotide was read an average of four times and at least once from each strand. RNA electrophoresis, blotting to Zeta-Probe membranes (Bio-Rad), and hybridization and washing (14) were performed as described (15). Rabbit genomic DN $\Lambda$ was prepared from the liver of a male New Zealand White rabbit by digestion with proteinase $\mathrm{K}$ and extraction with phenol (16). Human placental genomic DNA with a molecular weight greater than $50 \mathrm{~kb}$ was purchased from Clontech (Palo Alto, CA). DNA $(20 \mu \mathrm{g})$ was digested to completion with BamHI, EcoRI, or HindIII and subjected to electrophoresis at $5 \mathrm{~mA}$ on a $10-\mathrm{cm} 0.9 \%$ agarose gel. The fractionated DNA was transferred to Zeta-Probe membrane in $0.4 \mathrm{M} \mathrm{NaOH}$ following brief incubation of the agarose gel in $0.25 \mathrm{M} \mathrm{HCl} \mathrm{(17),} \mathrm{and} \mathrm{hybridized} \mathrm{in} 1.5 \times$ SSPE ( $1 \times$ SSPE is $180 \mathrm{mM} \mathrm{NaCl}, 10 \mathrm{mM}$ sodium phosphate buffer, $\mathrm{pH}$ 7.0 , and $10 \mathrm{mM}$ EDTA) containing $1 \%$ SDS and $0.5 \%$ dry milk, to $1-3$ $\times 10^{6} \mathrm{cpm} / \mathrm{ml}$ of ${ }^{32} \mathrm{P}$-labeled, nick-translated DNA probe at 65 (for rabbit DNA) or $61^{\circ} \mathrm{C}$ (for human DNA) for $16-24 \mathrm{~h}$. The filters with rabbit DNA were washed at $65^{\circ} \mathrm{C}$ twice with $0.1 \times \mathrm{SSC}(1 \times \mathrm{SSC}$ is $150 \mathrm{~mm}$ $\mathrm{NaCl}$ in $15 \mathrm{mM}$ sodium citrate buffer, $\mathrm{pH} 7.0$ ) containing $0.1 \%$ SDS for $30 \mathrm{~min}$ each, and those with human DNA were washed at $61^{\circ} \mathrm{C}$ with $0.5 \times$ SSC containing $1 \%$ SDS. cDNA probes were isolated electrophoretically from LMP agarose (BRL), purified with the use of Qiagen-tip 20 (Qiagen, Studio City, CA), and radiolabeled with a nick-translation kit from BRL. The sources of all other materials have been reported previously $(4,18)$.

\section{RESULTS AND DISCUSSION}

Identification of $P 450 N M b c D N A$ clones. A cDNA library constructed from rabbit nasal poly $(\mathrm{A})^{+} \mathrm{RNA}$ and cloned in $\lambda$ ZAP II vector was screened with monospecific sheep anti-NMb IgG (5), and eight immunopositive clones were isolated after three rounds of plaque purification. The identity of these clones as NMb-like was confirmed by Western blot analysis of the total cell lysate after induction of the cloned fusion protein by isopropylthiogalactoside (data not shown). Two of the clones, pb-42 and pb-93, produced fusion proteins that migrated slightly slower than the purified rabbit NMb on SDS-PAGE, which suggested that they contain cDNA inserts that encode full-length or near-full-length $\mathrm{NMb}$, as the fusion proteins should contain only 37 amino acid residues from the $\beta$-galactosidase gene. A third clone, pb-54, produced an immunoreactive fusion protein that migrated much faster than NMb on SDS-PAGE. Initial DNA sequence analysis revealed that the peptides encoded by the cDNA inserts from pb-42 and pb-93 partially overlap with purified $\mathrm{NMb}$ in amino acid sequence at the $\mathrm{NH}_{2}$-terminus, with the first residue of the cloned peptide corresponding to residue 21 or 12 of $\mathrm{NMb}$, respectively. Restriction mapping (Fig. 1) indicates that pb-93 contains a 1240 -bp cDNA insert while pb-42 contains a 2500 -bp cDNA insert. The composite nucleotide sequence of pb-93 and pb-42 
GCT CTC TGC TTC TCC TGC CTG CTC ATC CTC ATT GCC TGG AAA CGA GTC CAG AAG CCG

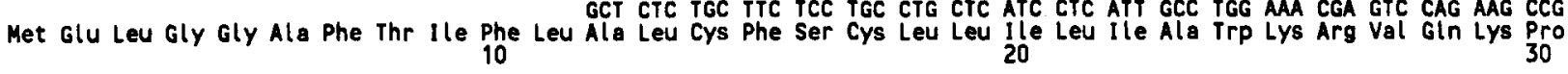

GGG AGG CTG CCC CCA GGC CCC ACT CCG ATT CCT TTC CTG GGG AAC CTG CTC CAA GTC CGC ACC GAC GCC ACC TIC CAG TCG ITC CTG AAG Gly Aro Leu Pro Pro Gly Pro Thr Pro 140 Pro Phe Leu Gly Asn Leu Leu Gln Val Arg Thr Asp Ala Thr Phe Gln Ser Phe Leu Lys

CTC AGG GAG AMA TAT GGC CCC GTG ITC ACC GTG TAC ATG GGC CCC CGG CCG GTA GTT ATT CTG TGT GGA CAT GAA GCA GTG AAG GAG GCT Leu Arg Glu Lys Tyr Gly pro Val Phe Thr Val Tyr Met Gly pro Arg Pro Val Val ग̣ile Leu Cys Gly his Glu Ala Val Lys Glu Ala

CTC GTG GAC CGA GCC GAC GAG TTC AGT GGC CGT GGA GAA CTG GCT TCG GTG GAG CGG AAT TIT CAA GGT CAT GGT GTA GCT CTG GCC AAT Leu Val Asp Arg Ala Asp Glu Phe Ser Gly Arg Gly Glu Leu Ala Ser Val Glu Arg Asn Phe Gln Gly His Gly val Ala Leu Ala Asn

GGG GAG CGG TGG CGG ATT CTT CGC CGC TTC ICG CTG ACC ATC CTG CGC GAC ITC GGC ATG GGG Aag CGC AGC ATC GAG GAG CGG ATC CAG Gly Glu Arg Trp Arg Ile Leu Arg Arg phe Ser Leu Thr Ile Leu Arg Asp Phe Gly Met Gly Lys Arg Ser Ile Glu Glu Arg Ile Gln

GAG GAA GCT GGC TAC TTG CTG GAG GAA TIC CGG AAG ACC AAA GGT GCG CCC ATC GAC CCC ACC TIC ITC CTG AGC CGC ACC GTC TCC AAT Glu Glu Ala Gly Tyr Leu Leu Glu Glu Phe Arg Lys thr Lys Gly Ala Pro Ile Asp Pro thr Phe Phe Leu Ser Arg Thr Val Ser Asn

GTC ATC AGC TCC GTG GTG IIT GGA AGC CGC IIT GAC IAC GAG GAC AAG CAG ITC CTG AGC CTG CTG AGG ATG ATC AAC GAG AGC ITC ATT

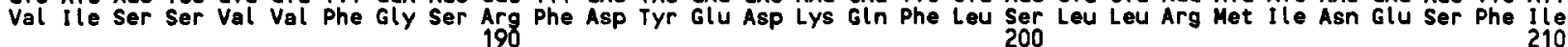

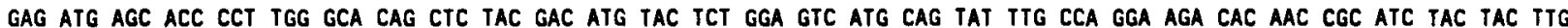
Glu Met ser Thr pro trp ala gln Leu Tyr Asp met Tyr ser Gly val Met Gln tyr Leu pro Gly arg his asn arg ile tyr tyr Leu

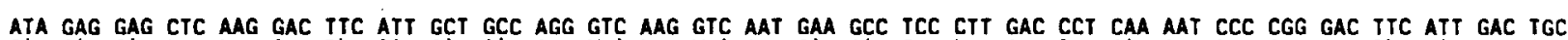
İe Glu Glu Leu Lys Asp phe Ile Ala Ala Arg Val Lys Val Asn Glu Ala Ser Leu Asp Pro Gln Asn Pro Arg Asp Phe ille Asp Cys

TTC CTC ATT Aag ATG CAC CAG GAT MAG MAT AAT CCC CAC ACA GAA TTC AaC CTC AaG AaC TTG GTC CTC ACT ACC CTC AAC CTC TTC ITT Phe Leu ile Lys Met His Gln Asp lys Asn Asn Pro his thr Glu Phe Asn Leu lys Asn leu Val Leu Thr thr Leu Asn Leu Phe phe 280 Asn Pro His Thr Glu Phe Asn LeU Lys 290

GCT GGC ACG GAA ACA GTG AGC TCC ACC CTG CGC TAC GGA TTC TTG CTG ATA ATG AAG CAC CCT GAA GTG CAA ACC AAG ATC TAT GAA GAG Ala Gly Thr Glu Thr Val Ser Ser Thr Leu Arg Tyr Gly Phe Leu Leu ile Met Lys His pro Glu Val Gln thr Lys Ile Tyr Glu Glu

ATT AAT CAA GTG ATC GGA CCA CAC CGG ATC CCA AGT GTG GAC GAC CGT GTC AAG ATG CCC TTC ACC GAC GCC GTG ATC CAC GAG ATC CAA Ile Asn Gln Val Ile Gly Pro his arg Ile Pro Ser Val Asp Asp Arg Val Lys Met Pro Phe thr Asp ala Val Ile His Glu Ile Gln 340

AGG CTG ACG GAC ATC GTG CCC ATG GGC GTC CCT CAC AAC GTC ATC CGG GAC ACT CAC TTC CGA GGC TAC CTT CTG CCC AAG GGC ACG GAC Arg Leu Thr Asp ile Val Pro Met Gly Val Pro His Asn Val Ile Arg Asp Thr His Phe Arg Gly Tyr Leu Leu Pro Lys Gly Thr Asp

GTG ITT CCC CTG CTG GGC TCA GTC CTC AAA GAC CCC AAA TAC TIC IGC CAC CCA GAC GAC ITC IAC CCC CAA CAC ITC CTG GAC GAG CAG Val Phe Pro leu Leu Gly Ser Val Leu Lys Asp Pro Lys Tyr Phe Cys His Pro Asp Asp Phe Tyr Pro Gin his Phe Leu Asp Glu Gln 420

GGC CGC TTC AAG AAA AAC GAA GCA TTC GTG CCG TIT TCC TCT GGA AAA CGC ATC TGC CTG GGC GAG GCC ATG GCC CGC ATG GAG CTC ITT Gly Arg Phe Lys Lys Asn Glu Ala phe Val Pro phe Ser Ser Gly Lys Arg Ile cys Leu Gly glu Ala Met ala Arg Met Glu Leu Phe

CTC TAC ITC ACC TCC ATC CTC CAG AAC TIC TCT CTG CAC CCG CTG GTG CCG CCC GTC AAC ATT GAC ATC ACT CCC AAG ATC TCG GGG TIT Leu Tyr Phe Thr ser Ile Leu Gln Asn Phe Ser Leu His Pro Leu Val Pro Pro Val Asn ille Asp ile thr Pro Lys ile Ser Gly Phe GGC AAC ATC CCT CCG ACC TAT GAG CTC TGC CTC ATC GCG CGC TGA GCAGTCTCCCCGGGGCAGAgagagaAgTGGGGGaGAaCGGAGCTCTGCCCGGTGTCGCG Gly Asn Ile Pro Pro Thr Tyr Glu Leu Cys Leu ile Ala Arg End

CCAGCCACGGTCCTCACTCTCCACATTCTGACAACAAACCCAAGAGGAGGCACTGITACTACCGCGTGGGAAGCTGACCTGAAGACCCGGAGCT GGGTGTCTTCTCCAGCCAGTAGAAG AGCAATACTTCTCCAAGATTITGGCCGAAGCCTGTAGGTTTAATGTTTGCIGGCTICTGCTITGCTICCTGCCAGIACCCAGACTCTGGT TGTAGATTCTGTCITCACGTCGTCCCTIT

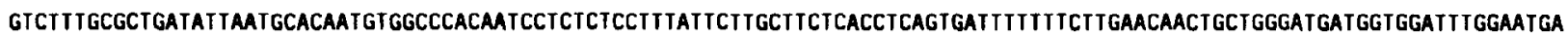
GgATCAAAACIAGTATAAAATGCTATGTCAGGTAACCCATITGTATAGGCTGGATTATATGAGATIGATCAAGATTGCTTAATTTTATAATCCCATGTGCTGCCATCACTCAACAGTAA GGAAGGCCTAGTAATAGTACCTAACTTTACAATGTAAAAGTAATTAAAATGCTATTGAAACCAAATGATAGGCGATCCTTACAGTAAATTTATTTTGACCTCTTCTGCATGGTATCCTC

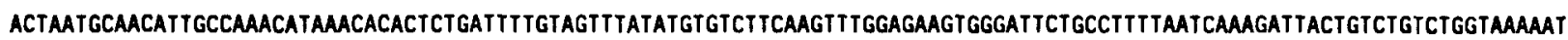

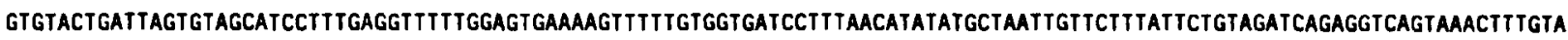

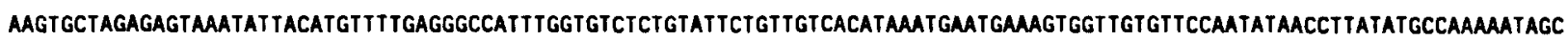
ITTGgGGCTGGATtTAACCTGGgCTAAAGTITGCTGACCCAGCTATAGATCATAAATACCATCCAAAACAAATGTG

687

777

867

957

FIG. 2. Nucleotide sequence encoding $\mathrm{P} 450 \mathrm{NMb}$ with derived amino acid sequence. The first 11 residues at the $\mathrm{NH}_{2}$-terminus of the amino acid sequence were previously determined by the Edman method (4). Nucleotides are numbered to the right of each line and amino acids are numbered below the corresponding residues. A potential site for phosphorylation (residues 128-131) is underlined, and the predicted active site cysteine residue at position 439 is underlined twice. The asterisk at position 46 indicates a difference between the predicted amino acid sequence and that determined by Edman degradation (Glu). The sequence was determined from clones pb-93 and pb-42. 
(Fig. 2) is 2539 bp in length and contains an open reading frame that begins at position 1 and extends through position 1446. The first 39 amino acids of this reading frame correspond to residues $12-50$ of $\mathrm{P} 450 \mathrm{NMb}$ determined previously by Edman degradation (4), except at position 46 , where Leu was predicted from the nucleotide sequence but Glu was detected by Edman degradation. Subsequent sequence analysis of two additional positive clones gave the same results, with Leu at position 46 . Since the background level of Leu in late cycles of Edman degradation mixture was rather high, a small increase may not have been detectable. Therefore, both Leu and Glu may have been present in cycle 46 , possibly as a result of allelic differences at this position; in this connection it should be noted that NMb was purified from the combined nasal tissue of a large number of animals. Thus the complete polypeptide, as shown in Fig. 2, contains 494 amino acid residues and has a calculated molecular weight of 56,635 .

Comparison of P450NMb to other P450 isozymes. The amino acid composition of $\mathrm{NMb}$ is similar to that of other sequenced P450 isozymes: $38.5 \%$ hydrophobic (Phe, Ile, Leu, Met, Val, Trp, and Tyr), $11.5 \%$ basic (Arg and Lys), and $11.1 \%$ acidic (Asp and Glu) residues. The protein contains three Trp and seven Cys residues, with the likely fifth heme ligand, Cys -439 , located in a region that is highly conserved among all other sequenced P450s. As indicated in Table I, NMb shows more than $50 \%$ sequence identity with members of the P450 gene II family, but $31 \%$ or less with members of gene families I, III, and IV. However, $83 \%$ sequence identity is found between $\mathrm{NMb}$ and rat P450olf1 (rat P450IIG1), and only half of the differences are nonconservative changes. An alignment of the sequence of $\mathrm{NMb}$ and that of P450olf1 (Fig. 3) indicates that the unmatched amino acids are fairly evenly

\section{TABLE I}

Similarity of Amino Acid Sequences between P450NMb and 10 Other Forms of Microsomal Cytochrome P450

\begin{tabular}{|c|c|c|c|c|}
\hline \multirow[b]{2}{*}{ Trivial name $^{b}$} & \multicolumn{3}{|c|}{$\begin{array}{l}\text { Name based on proposed } \\
\text { evolutionary relationships }\end{array}$} & \multirow[b]{2}{*}{$\%$ Identity } \\
\hline & Family & Subfamily & Gene & \\
\hline 1 & II & $\mathrm{C}$ & 5 & 52.6 \\
\hline 2 & II & $\mathrm{B}$ & 4 & 57.7 \\
\hline $3 a$ & II & $\mathrm{E}$ & 1 & 51.2 \\
\hline $3 b$ & II & C & 3 & 50.2 \\
\hline $3 \mathrm{c}$ & III & A & 6 & 26.4 \\
\hline $3 d$ & II & $\mathrm{E}$ & 2 & 51.1 \\
\hline 4 & I & A & 2 & 31.0 \\
\hline 5 & IV & B & 1 & 23.2 \\
\hline 6 & I & A & 1 & 31.6 \\
\hline olf1 & II & G & 1 & 82.8 \\
\hline
\end{tabular}

a See Nebert et al (2) for protein sequence references.

${ }^{b} \mathrm{P} 450 \mathrm{olf} 1$ is from rat; all other $\mathbf{P} 450$ forms are from rabbit.

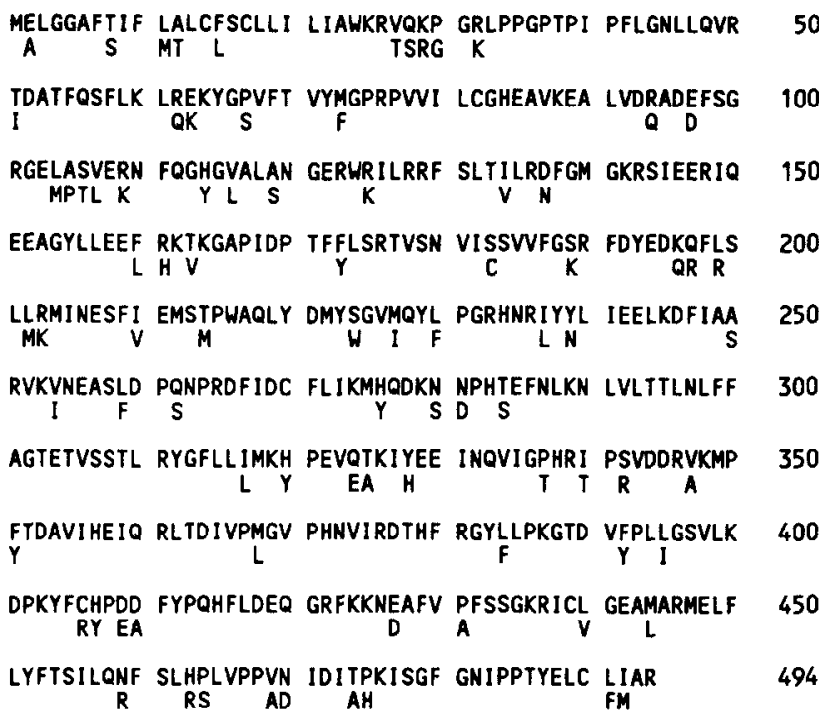

FIG. 3. Alignment of rabbit $\mathrm{P} 450 \mathrm{NMb}$ with rat $\mathrm{P} 450$ olf1. The deduced amino acid sequence for $\mathrm{NMb}$ is shown with the substitutions in P450olf1 indicated below. Amino acids are numbered from the Met at the amino terminus of $\mathrm{NMb}$.

distributed throughout the sequence. The $\mathrm{NH}_{2}$-terminal Met residue is missing in the predicted sequence based on P450olf1 cDNA, but is encoded for in the genomic sequence (19). A single potential site for Ser/Thr phosphorylation by the cAMP-dependent protein kinase (ArgArg-Phe-Ser, as shown in Fig. 2) is found at position 131 of $\mathrm{NMb}$, and is also present in P450olf1 (9) as well as in many other $\mathrm{P} 450$ proteins (20).

We are assigning rabbit $\mathrm{P} 450 \mathrm{NMb}$ to the IIG subfamily on the basis of sequence homology and are tentatively designating it as P450IIG1 because of the $83 \%$ similarity with respect to rat $P 450$ olf 1 . However, more information is needed about other possible members of the IIG gene family in various species before a final decision can be reached. P-450NMa, on the other hand, is apparently not a member of the $\mathrm{IIG}$ subfamily as judged by the $\mathrm{NH}_{2}$ terminal amino acid sequence and immunochemical comparisons $(4,5)$.

RNA hybridization analysis. No signal was detected when poly $(\mathrm{A})^{-1} \mathrm{RNA}$ from various rabbit tissues, including liver, kidney, intestine, and lung, was fractionated electrophoretically and the RNA blots were hybridized with DNA probes corresponding to the coding sequence of $\mathrm{NMb}$ (data not shown). This finding is in agreement with the tissue-specific expression observed in our recent immunochemical study (5). Interestingly, two bands were detected when radiolabeled pb-93 was hybridized to poly $(\mathrm{A})^{+}$RNA from rabbit olfactory mucosa (Fig. 4, lane 1 ), corresponding to mRNAs of approximately 2.1 and $3.6 \mathrm{~kb}$ in length. A similar pattern was obtained when the blot was rehybridized with the $S m a \mathrm{I}-P s t \mathrm{I}$ restriction fragment of pb-54, which contains solely 3 '-nontranslated sequence (lane 2). However, when the blot was rehybrid- 


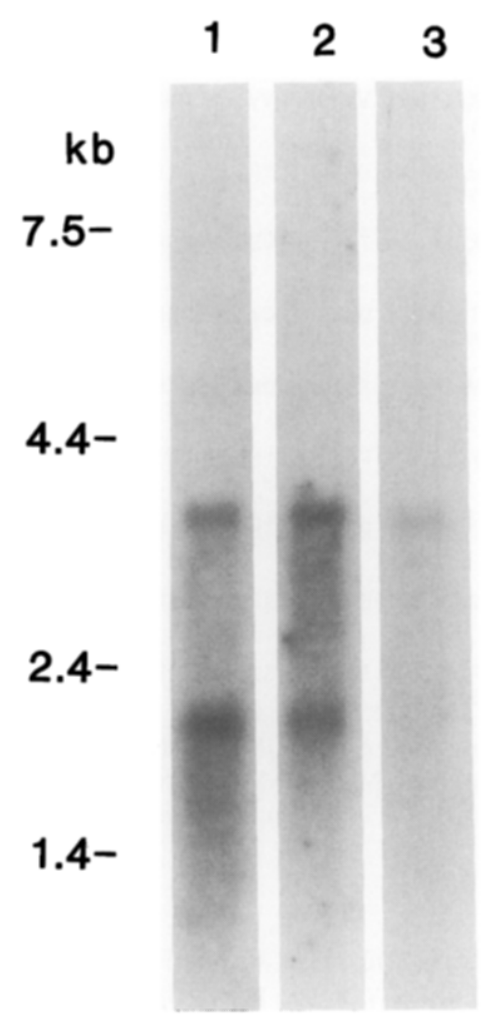

FIG. 4. Northern blot analysis of rabbit nasal RNA. Poly $(A)^{+}$RNA $(5 \mu \mathrm{g})$ from rabbit olfactory mucosa was fractionated by electrophoresis, transferred to a Zeta-Probe membrane, and sequentially hybridized with probes corresponding to different segments of the NMb cDNA: pb-93 cDNA insert (coding sequence, lane 1); pb-54, SmaI-Pst I fragment ( $3^{\prime}$ nontranslated sequence, lane 2); and pb-54, PstI-EcoRI fragment ( 3 'nontranslated sequence, lane 3 ). After each hybridization the radiolabeled probe was removed by treatment with $0.5 \%$ SDS in $0.1 \times$ SCC at $95^{\circ} \mathrm{C}$, and the blot reexposed to ensure that the probe had been removed. The positions of selected fragments of the 0.24 - to $9.5-\mathrm{kb}$ RNA ladder from BRL are indicated.

ized with the $3^{\prime} P s t \mathrm{I}-E c o$ RI restriction fragment of pb54 , which corresponds to the extreme $3^{\prime}$ end of our $\mathrm{NMb}$ cDNAs (see Fig. 1), the 3.6-kb band was detected as a major band with little, if any, hybridization of the probe to the $2.1-\mathrm{kb}$ band (lane 3 ). These results suggest that the smaller mRNA is polyadenylated in the vicinity of and probably $3^{\prime}$ to the PstI site; however, inspection of the pb-42 3'-nontranslated sequence does not reveal a typical polyadenylation signal (AATAAA). Although there are several possible alternative polyadenylation signals in the 3 -nontranslated segment of $\mathrm{pb}-42$, it is unclear whether the smaller mRNA results from the use of one of these signals or from allelic differences or alternative splicing of the $\mathrm{NMb}$ gene transcript. Nef et al. $(9,19)$ reported that two mRNA species were observed in RNA derived from rabbit olfactory epithelium when probed with P450olf1 cDNA encoding exons 1 to 5 , whereas only one class of mRNA was detected in bovine or rat olfactory epithelium.
Genomic DNA hybridization analysis. To estimate the complexity of the P450IIG subfamily, electrophoretically fractionated rabbit liver DNA was hybridized to a nearfull-length cDNA insert from pb-42 (Fig. 5A) or to a fragment from the 3 '-nontranslated region of pb-54 (Fig. 5B). The stringency of hybridization in these experiments was such that only sequences with greater than $80 \%$ identity would be detected. Digestion with three restriction enzymes revealed simple hybridization patterns indicative of a single gene in the rabbit P450IIG subfamily. Thus, with the near-full-length probe (Fig. $5 \mathrm{~A}$ ), a 7 -kb band and two bands at about $4.5 \mathrm{~kb}$ were found in the Bam HI digest, and four bands representing a total of at least $15 \mathrm{~kb}$ of DNA were found in the EcoRI digest. In the HindIII digest, although only a single major band of about $7 \mathrm{~kb}$ was detected, this may represent a doublet, thus totaling 14 $\mathrm{kb}$ of hybridizable DNA. With the 3 '-specific probe, only a single hybridizing band of between 7 and $8 \mathrm{~kb}$ was found in all three digests (Fig. 5B). The indication that only one copy of the $\mathrm{NMb}$ gene is present in the rabbit genome argues that the multiple mRNA species seen on the RNA blot are not derived from two different genes. A single gene, which is at least $11 \mathrm{~kb}$ in size, was also found in the rat IIG subfamily (19). Hybridizations with human genomic DNA (not shown) indicate that at least one copy of the homologous gene of rabbit NMb cDNA is present in the human genome. However, it remains to be determined whether an ortholog of rabbit olfactory-specific $\mathrm{P} 450 \mathrm{NMb}$ is expressed in human tissues.

As proposed earlier $(4,8)$, one or more of the nasal forms of P450 may be involved in the disposal of various

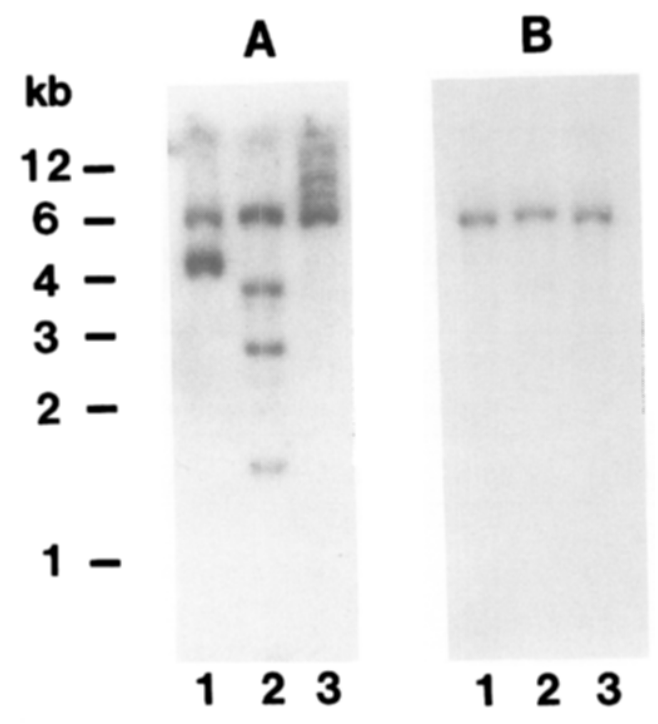

FIG. 5. Hybridization of rabbit genomic DNA to the P450NMb cDNA. DNA $(20 \mu \mathrm{g})$ from rabbit liver was digested with BamHI (lane 1), EcoRI (lane 2), or HindIII (lane 3), and hybridized as described under Materials and Methods. The filter was probed with the cDNA insert from pb-42 (near full length, A) or with the 3 '-nontranslated SmaI-Pst I fragment from pb-54 (B). The positions of selected fragments of the 1-kb DNA ladder from BRL are indicated. 
odorants that are deposited on the nasal mucosa, thereby maintaining acuity in the sense of smell. The occurrence of $\mathrm{P} 450 \mathrm{NMb}$ in the olfactory mucosa but not the respiratory mucosa or a variety of other tissues is consistent with this hypothesis, as is the observation (19) that in the rat the activation of the P450IIG1 gene closely parallels the appearance of a sensitive odorant-stimulated neurosensory response. The intriguing possibility of a function for this cytochrome in olfactory chemoreception, as well as an improved understanding of the relative roles of $\mathrm{P} 450 \mathrm{~s} \mathrm{NMa}$ and $\mathrm{NMb}$ in the oxidation of a variety of exogenous and endogenous compounds such as ethanol and testosterone and in the activation of nasal procarcinogens (4), is an interesting subject that requires further investigation.

\section{REFERENCES}

1. Black, S. D., and Coon, M. J. (1987) Adv. Enzymol. Relat. Areas Mol. Biol. 60, 35-87.

2. Nebert, D. W., Nelson, D. R., Adesnik, M., Coon, M. J., Estabrook, R. W., Gonzalez, F. J., Guengerich, F. P., Gunsalus, I. C., Johnson, E. F., Kemper, B., Levin, W., Phillips, I. A., Sato, R., and Waterman, M. R. (1989) DNA 8, 1-13.

3. Waterman, M. R., John, M. E., and Simpson, E. R. (1986) in Cytochrome P-450 (Ortiz de Montellano, P. R., Ed.), pp. 345-386, Plenum, New York.

4. Ding, X., and Coon, M. J. (1988) Biochemistry 27, 8330-8337.

5. Ding, X., and Coon, M. J. (1990) Mol. Pharmacol. 37, 489-496.
6. Ding, X., Koop, D. R., Crump, B. L., and Coon, M. J. (1986) Mol. Pharmacol. 30, 370-378.

7. Reed, C. J., Lock, E. A., and De Matteis, F. (1986) Biochem. J. 240, 585-592.

8. Dahl, A. R., Hadley, W. M., Hahn, F. F., Benson, J. M., and McClellan, R. O. (1982) Science (Washington, D.C.) 216, 57-59.

9. Nef, P., Heldman, J., Lazard, D., Margalit, T., Jaye, M., Hanukoglu, I., and Lancet, D. (1989) J. Biol. Chem. 264, 6780-6785.

10. Chirgwin, J. M., Przybyla, A. E., MacDonald, R. J., and Rutter, W. J. (1979) Biochemistry 18, 5294-5299.

11. Aviv, H., and Leder, P. (1972) Proc. Natl. Acad. Sci. USA 69, 1408 1412.

12. Mierendorf, R. C., Percy, C., and Young, R. A. (1987) in Methods in Enzymology (Berger, S. L., and Kimmel, A. R., Eds.), Vol. 152, pp. 458-469, Academic Press, San Diego.

13. Sanger, F., Nicklen, S., and Coulson, A. R. (1977) Proc. Natl. Acad. Sci. USA 74, 5463-5467.

14. Maniatis, T., Fritsch, E. F., and Sambrook, J. (1982) in Molecular Cloning: A Laboratory Manual, pp. 200-201, Cold Spring Harbor Laboratory, Cold Spring Harbor, NY.

15. Porter, T. D., Khani, S. C., and Coon, M. J. (1989) Mol. Pharmacol. 36, 61-65.

16. Blin, N., and Stafford, D. W. (1976) Nucleic Acids Res. 3, 23032308.

17. Reed, K. C., and Mann, D. A. (1985) Nucleic Acids Res. 13, 72077221.

18. Khani, S. C., Porter, T. D., Fujita, V. S., and Coon, M. J. (1988) J. Biol. Chem. 263, 7170-7175.

19. Nef, P., Larabee, T. M., Kagimoto, K., and Meyer, U. A. (1990) $J$. Biol. Chem. 265, 2903-2907.

20. Nelson, D. R., and Strobel, H. W. (1988) J. Biol. Chem. 263, 6038 6050 . 